\title{
How to Properly Dispose of Unwanted Medications ${ }^{1}$
}

\author{
Alexander J. Reisinger ${ }^{2}$
}

\section{Introduction}

According to the 2016 National Survey on Drug Use and Health, 6.2 million Americans abused controlled prescription drugs in the previous month (Substance Abuse and Mental Health Services Administration 2017). Furthermore, a majority of the abused prescription drugs were obtained from friends or family. There were $>2,500$ deaths due to prescription drug overdoses in 2015 in the state of Florida alone. Properly disposing of expired or unused medications is an important step towards reducing the prevalence and impacts of prescription drug abuse throughout Florida. In addition to preventing prescription drug abuse, properly disposing of unused medications prevents accidental ingestion and poisoning of children or pets, avoids the potential of accidentally taking the wrong medication, and prevents medications from entering streams, rivers, and wetlands by being poured down the drain. This publication is intended for residents within the state of Florida looking to dispose of unused medication waste in Florida.

\section{Never Flush Medications Down the Drain}

Everything that goes down the drain, whether through a sink, toilet, or shower, is routed through wastewater pipes to either a wastewater treatment plant or an on-site sewage treatment and disposal (septic) system, eventually returning to natural water bodies (Figure 1). These systems are not designed to remove pharmaceuticals and personal care products from wastewater. Therefore, these compounds can remain in solution until water is discharged into either surface waters or groundwater, contaminating these water bodies with pharmaceutical substances (Verlicchi et al. 2012, Yang et al. 2017). Instead, either take unused, unwanted, or expired medications (including both prescriptions and over-the-counter drugs) to a drug take-back program or dispose of them via proper household disposal procedures. For more information on the use of medications and the environmental impacts of improperly disposing of medications in the United States, see Contaminants in the Urban Environment: Pharmaceuticals and Personal Care Products (PPCPs) - Part 1 (http://edis.ifas.ufl.edu/ss632) and Contaminants in the Urban Environment: Pharmaceuticals and Personal Care Products (PPCPs) -Part 2 (http://edis.ifas.ufl. edu/ss633).

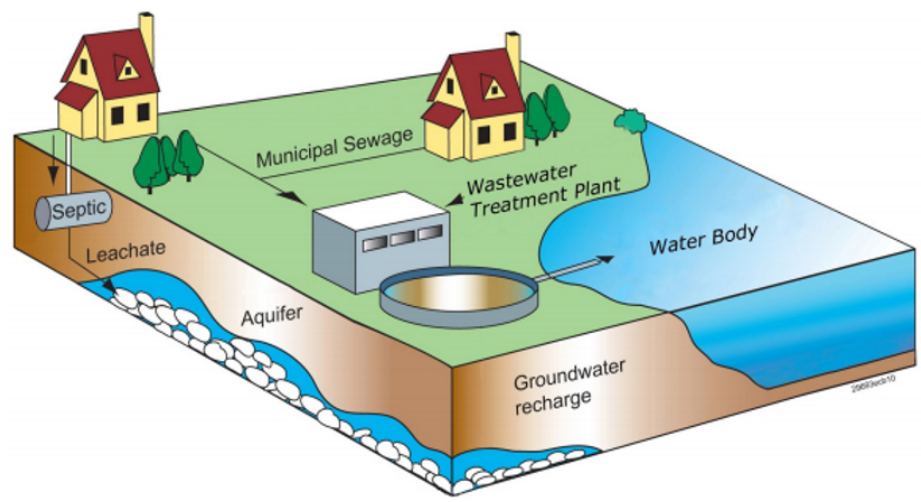

Figure 1. Examples of how residential wastewater is connected to groundwater and surface water bodies.

Credits: EPA (https://www.epa.gov/sites/production/files/2015-06/ documents/how-to-dispose-medicines.pdf; accessed 7 May 2018)

1. This document is SL467, one of a series of the Department of Soil and Water Sciences, UF/IFAS Extension. Original publication date March 2020. Visit the EDIS website at https://edis.ifas.ufl.edu for the currently supported version of this publication.

2. Alexander J. Reisinger, assistant professor, Department of Soil and Water Sciences, Center for Landscape Conservation and Ecology; UF/IFAS Extension, Gainesville, FL 32611.

The Institute of Food and Agricultural Sciences (IFAS) is an Equal Opportunity Institution authorized to provide research, educational information and other services

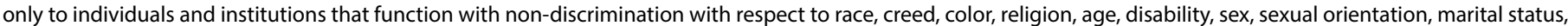

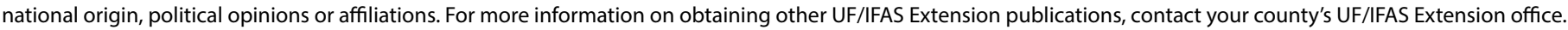
U.S. Department of Agriculture, UF/IFAS Extension Service, University of Florida, IFAS, Florida A \& M University Cooperative Extension Program, and Boards of County Commissioners Cooperating. Nick T. Place, dean for UF/IFAS Extension. 


\section{Best Option: Drug Take-Back Locations or Events}

The best way to dispose of unwanted medications is to bring them to an expert that knows how to properly dispose of them. The United States Drug Enforcement Administration (DEA) regularly sponsors National Prescription Take Back Days, typically occurring biannually in April and October (Figure 2).

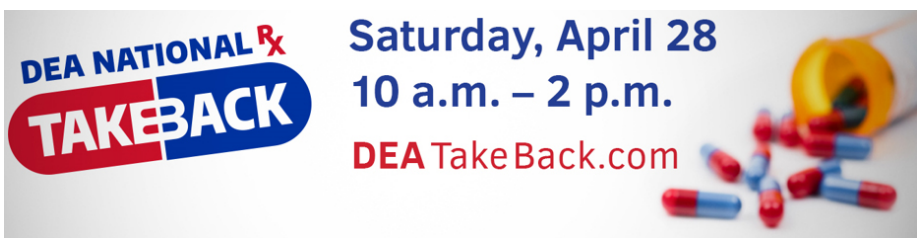

Figure 2. Example of an advertisement for the DEA National Drug Take Back Day.

Credits: DEA

Trash and recycling services offered by city and county governments may also provide this service. Additionally, many sheriff's offices and police departments throughout the state of Florida offer anonymous medication drop-off locations. Finally, pharmacies may provide drop-off locations within their stores (Figure 3). In order to identify the best location or event to bring your unwanted medications for disposal, you may contact your local trash and recycling service, your sheriff's office or police department, or your nearby pharmacy. In lieu of contacting these organizations, a list of year-round controlled substance public disposal locations can be found at https://apps.deadiversion.usdoj. gov/pubdispsearch/spring/main?execution=e1s1.

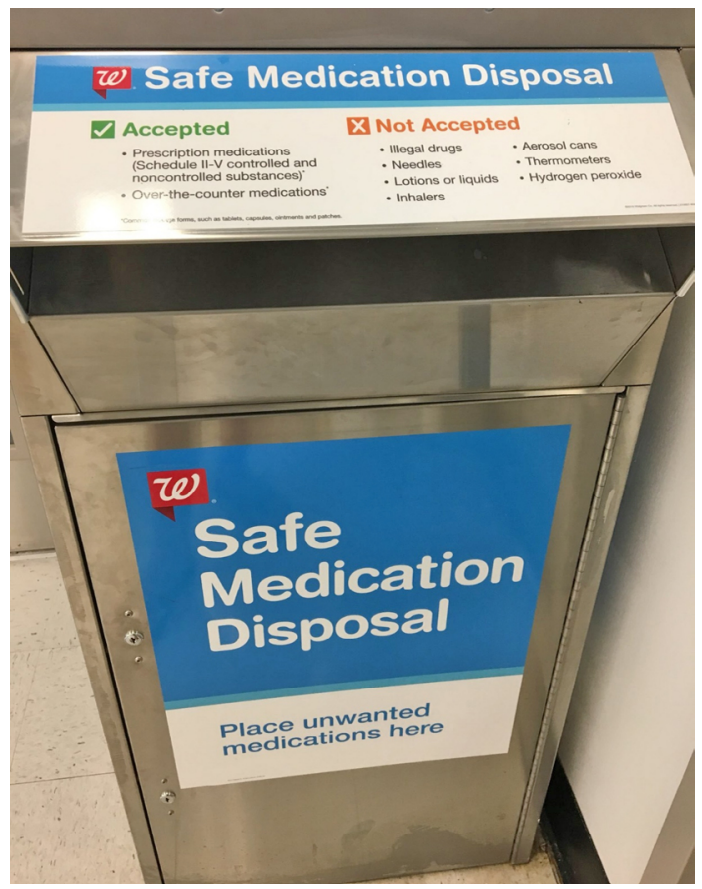

Figure 3. Anonymous medication disposal drop-off box offered by a pharmacy in Gainesville, FL.

Credits: Alexander Joseph Reisinger

\section{Alternative Option: Household Disposal}

If there are no drug take-back locations or events near you, or if you are unable to bring your unwanted medications to these locations/events for any reason, the alternative option is to dispose of unwanted medications with your other household waste. There are five steps for proper household disposal as recommended by the US Environmental Protection Agency (EPA):

1. Take your prescription drugs out of their original container(s).

2. Mix drugs with an undesirable substance, such as cat litter or used coffee grounds. (This step prevents accidental consumption of the medications by children or animals.)

3. Put the mixture into a disposable container with a lid, such as an empty margarine tub, or into a sealable bag.

4. Conceal or remove any personal information, including prescription $(\mathrm{Rx})$ number, from the original prescription container(s) by covering it with permanent marker or duct tape, or by scratching it off.

5. Place both the sealed container with the drug mixture and the empty drug containers into the trash.

By disposing of your unwanted medications with your household waste rather than down the drain with your wastewater, these medications are deposited in a landfill. It would take a long time for the contaminants to be transported from a landfill to sensitive water bodies, allowing increased time for microbial and chemical processes to degrade these contaminants.

\section{Summary}

Prescription drug abuse is a major problem in the United States and the state of Florida. Properly disposing of unwanted medication can reduce access to these medications. Furthermore, proper disposal of unwanted medications prevents accidental ingestion by children and pets, and limits the potential for export of medications from wastewater treatment systems into the environment. The best way to dispose of unwanted medications is to bring them to a collection facility or take-back event. If these are not available, EPA guidelines on proper disposal of unwanted medications in household waste should be followed. 
More information on how to properly dispose of unwanted medications is available at the EPA webpage for Collecting and Disposing of Unwanted Medicines (https://www.epa. gov/hwgenerators/collecting-and-disposing-unwantedmedicines) and the DEA National Drug Take Back Day website (https://takebackday.dea.gov/).

\section{References}

Florida Department of Health. 2017. "2016-2017 Prescription Drug Monitoring Program Annual Report." http:// www.floridahealth.gov/statistics-and-data/e-forcse/ funding/2017pdmpannualreport.pdf. Accessed 7 May 2018.

Substance Abuse and Mental Health Services. 2017. "Key Substance Use and Mental Health Indicators in the United States: Results from the 2016 National Survey on Drug Use and Health (HHS Publication No. SMA 17-5044, NSDUH Series H-52)." Rockville, MD: Center for Behavioral Health Statistics and Quality, Substance Abuse and Mental Health Services Administration. https://www.samhsa.gov/data. Accessed 7 May 2018.

United States Environmental Protection Agency. 2011. "How to Dispose of Medicines Properly." Report from the Office of Water, EPA 816-F-11-003. https://www.epa.gov/ sites/production/files/2015-06/documents/how-to-disposemedicines.pdf. Accessed 7 May 2018.

Verlicchi, P., M. Al Aukidy, and E. Zambello. 2012. "Occurrence of Pharmaceutical Compounds in Urban Wastewater: Removal, Mass Load and Environmental Risk after a Secondary Treatment-A Review." Science of the Total Environment 429: 123-155. https://doi.org/10.1016/j. scitotenv.2012.04.028.

Yang, Y.-Y., G. S. Toor, P. C. Wilson, and C. F. Williams 2017. "Micropollutants in Groundwater from Septic Systems: Transformations, Transport Mechanisms, and Human Health Risk Assessment." Water Research 123: 258-267. https://doi.org/10.1016/j.watres.2017.06.054 